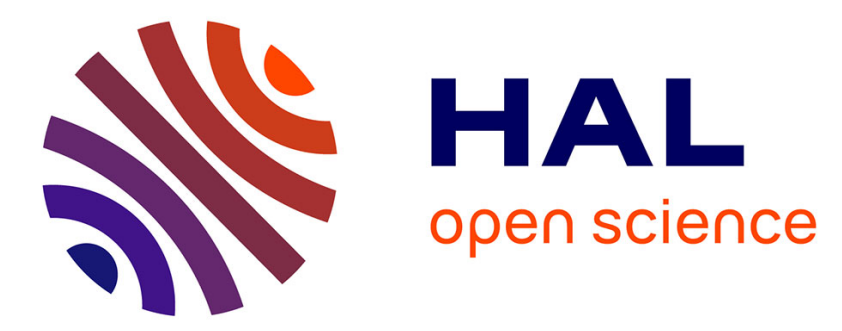

\title{
Analysis of the Polyethylene Terephthalate Production Chain: An Approach Based on the Emergy Synthesis
}

Gustavo Bustamante, Biagio F. Giannetti, Feni Agostinho, Cecília Almeida

\section{To cite this version:}

Gustavo Bustamante, Biagio F. Giannetti, Feni Agostinho, Cecília Almeida. Analysis of the Polyethylene Terephthalate Production Chain: An Approach Based on the Emergy Synthesis. IFIP International Conference on Advances in Production Management Systems (APMS), Sep 2016, Iguassu Falls, Brazil. pp.798-804, 10.1007/978-3-319-51133-7_93 . hal-01615807

\section{HAL Id: hal-01615807 https://hal.inria.fr/hal-01615807}

Submitted on 12 Oct 2017

HAL is a multi-disciplinary open access archive for the deposit and dissemination of scientific research documents, whether they are published or not. The documents may come from teaching and research institutions in France or abroad, or from public or private research centers.
L'archive ouverte pluridisciplinaire HAL, est destinée au dépôt et à la diffusion de documents scientifiques de niveau recherche, publiés ou non, émanant des établissements d'enseignement et de recherche français ou étrangers, des laboratoires publics ou privés. 


\title{
Analysis of the Polyethylene Terephthalate Production Chain: An Approach Based on the Emergy Synthesis
}

\author{
G. Bustamante, B. F. Giannetti, F. Agostinho, and C.M.V.B. Almeida \\ Paulista University, São Paulo, Brazil \\ gustamante1000@hotmail.com
}

\begin{abstract}
The petrochemical industry is characterized by the intense use of non-renewable resources, such as crude oil, associated to a high environmental load derived from efforts from nature and human systems to produce these products. These efforts may be accounted for by emergy synthesis, which is a tool that determines the amount of energy, directly or indirectly, necessary to obtain a product or service by means of a common unit (solar equivalent Joules seJ). In this work, emergy synthesis is applied to the polyethylene terephthalate (PET) production chain in the European petrochemical sector. The unit emergy values (UEV) of the system products are estimated, enabling comparative interpretations among the quality of energy usage and processes' efficiency.
\end{abstract}

Keywords: Emergy · Specific emergy · Environmental accounting · Petrochemical industry · PET.

\section{Introduction}

The importance of the petrochemical industry lies in being a source of large amounts of intermediate products, which are the main raw materials for many other industries like plastic, automotive, transportation, textile and agriculture. However, the production processes with intensive usage of non-renewable natural resources are often associated with high environmental costs, especially in regard to the risk of resource depletion. Therefore, there is an increasing awareness concerning the environmental problems that may arise in the future due to the misuse of strategic non-renewable resources, such as crude oil. In the recent decades, different methods, techniques and research were developed providing knowledge about the specific environmental problems caused by the oil-based production systems. The emergy synthesis, developed by H. T. Odum [1], is an environmental accounting method, based on the laws of thermodynamics and systems ecology, to determine the amount of energy, directly or indirectly, required to produce a good or service. Since the emergy is measured in units of solar equivalent joules (seJ), coefficients called transformities, which represent the emergy intensity through the ratio of emergy (required by the process) to energy (embodied in the product) are used as conversion factors allowing accounting flows are not directly solar origin. The unit emergy values (UEV) refer 
to the relationship between the quantity of emergy per unit of mass, volume, area, etc., and include the transformities (seJ /J). The UEVs are a measure of energy quality and process efficiency, since the same amount of invested emergy can derive in different types of energy, with different capabilities to produce work and, therefore, different qualities.

Oil-based production systems have been evaluated using the emergy synthesis. Bastianoni et al. [2] determined the UEVs of oil and natural gas, according to the geological production process and proposed the use of average transformities between the new values and those calculated by Odum [1]. Later, these results were complemented with the estimation of the transformity of liquid petroleum products [3]. This transformity was used as the emergy contribution of naphtha in a study where different ethylene production processes were evaluated and compared using the emergy synthesis [4].

Another method widely used to evaluate the environmental burdens of products and process in petrochemical industry is the Life Cycle Assessment (LCA) $[5,6]$. This method allows estimations of environmental impacts related to different categories, such as global warming, energy use, ozone depletion and abiotic resource use. The complementarity of LCA and emergy synthesis [7] was proposed as an alternative approach, through the application of transformities to the data reported in life cycle inventories (LCI). In spite of the inconsistency issues addressed by Bakshi [8] to integrate both approaches, highlighting the differences of the analysis boundaries, the integration of both methods may provide a more comprehensive analysis, including not only the economic and environmental resources required by the production, but also the impact of their emissions [8]. LCIs are not conventional data sources for emergy synthesis, but some authors highlighted the accuracy and consistency of results based on this type of information [9]. Obstacles, limitations, restrictions and critical points of complementarity or integration of LCA and emergy methods are discussed in $[9,10]$.

Almeida et al. [11] applied the emergy accounting based on data from a previous Brazilian LCA study of the PET and aluminum packaging production chains for beverage, including the recycling stages. This analysis contributed for the selection of the materials and processes during the product design stage. In this case, the inventory data was based on the information reported by group of Brazilian companies, collected through questionnaires, including data on raw materials use and consumption, energy, semimanufactured and auxiliary materials and fuels for transport, considering only the Brazilian domestic production. The use of LCIs for calculating emergy was performed taking into account aspects about coherence of emergy algebra rules, the structure of the inventory data and the boundaries of the considered systems. In this work, similarly to Almeida et al. [11], the production of PET resin as preform for beverage packages is also analyzed. However, a more comprehensive analysis is sought regarding the specific emergies of eleven intermediates products that make up this petrochemical chain, considering each of its processes separately based on a different inventory for each intermediate product. The data structure used in this study has a higher 
level of detail since the eleven intermediate products are tracked back, considering the cumulative amounts of all the elementary flows throughout the life cycle of each one. More details about data sources and methods will be described in the following sections.

The objective of this study is to apply an LCI-based emergy synthesis to determine the UEVs of the products for and within the polyethylene terephthalate production chain (PET), based on the information about the European petrochemical production. These UEVs are compared with those obtained by Bastianoni et al. [3] and Sha et al. [4], calculated in the traditional way.

\section{Method}

\subsection{PET Production System}

Fig.1 shows the stages of the PET production chain. The first stage is the extraction and processing of crude oil and natural gas. These resources are a mixture of hydrocarbons which can be derived into chemical compounds that are used as raw material of other products along the production chain. The main fraction of crude oil used in the petrochemical industry is naphtha. The production route includes several unitary processes, each with an important contribution in the total balance of resources. At the end of the production chain, the thermoplastic resin in solid state (bottle-grade) is obtained, and used as raw material for the production of bottle packaging, via injection or blown.

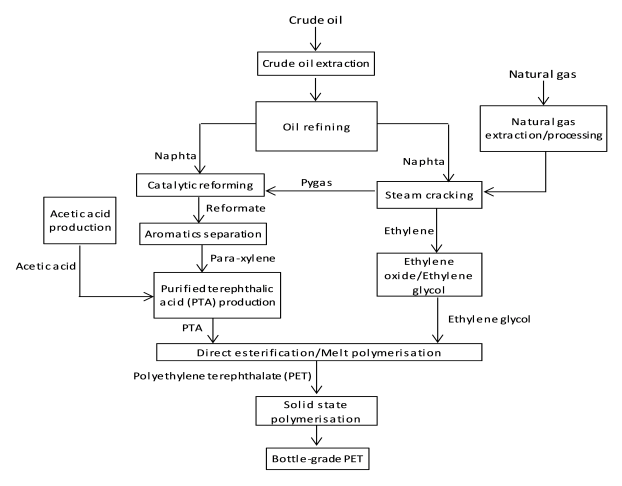

Fig. 1. Production route of polyethylene terephthalate (PET) bottle-grade (Source: adapted from [12])

\section{$2.2 \quad$ Emergy method}

Emergy is a measure in solar equivalent joules (seJ) of all contributions received by any system including the production ones. These contributions come in the 
form of material and energy flows, fuels, metals money, and labor. The result is a scientific measure of the energy previously used, directly or indirectly to obtain each flow. Emergy tracks all things to their source in the biosphere, the supplier, recognizing the environmental effort needed for the production of a good or service, in which lies the value of a resource, ensuring the use optimization [13].

The emergy results are presented in a common unit, called solar equivalent joules, seJ, and unit emergy values (UEV) are used for the conversion of one type of energy to another. The UEVs can be expressed as seJ / unit (e.g. grams, liters, currency) and the term transformity is used when the UEVs are expressed in seJ /J. As a measure of energy conversion and process efficiency, the UEVs refer to one unit of product that can be obtained from the lowest emergy investment.

The emergy tables are built based on the recorded information about the input and output flows of the system analyzed. The amount of each input is multiplied by its respective UEV, giving as a result the emergy of each input, which can be summed to determine the total emergy of the process and, thus, of the product. It should be noted that flows related to the plant construction phase, infrastructure and maintenance, were not taken into consideration in this work, since their influence in the total emergy required is around $4 \%$, and considered negligible [3,4]. Similarly, since this study intends to evaluate only the technological efficiency of each process, labor and services inputs are not included. These flows depend, to a large extent, on the local social and economic structures, and consequently, limit the assessment to a given region and the overall scope of the analysis restricted. As the results refer to technological aspects, they can be used for comparison with other production systems of the same products, and assist strategic decision making.

\subsection{LCI Databases}

The databases comprise flows that are the result of tracking back each product along the production chain, including upstream processes as many as needed to identify the environmental source. Hence, the only economic or transformed output in the resulting data is the functional unit: $1 \mathrm{~kg}$ of product ("at gate" representing the average of European industrial production). All other values correspond to cumulative totals of all operations traced back to the extraction of raw materials from nature [14]. Such information is contained in documents known as Eco-profiles, which include all streams belonging to the processes from the extraction of natural resources to obtaining $1 \mathrm{~kg}$ of each product, ready for transport or transfer to the consumer. The Eco-profiles are established following the ISO 14040-44 standards and the International Reference Life Cycle Data System (ILCD) ${ }^{1}$. The databases used in this work are part of the Eco-profile Program and Environmental Product Declaration (EPD) of the Association of Plastics Manufacturers, PlasticsEurope.

\footnotetext{
${ }^{1}$ Details about the Eco-profiles methodology, interpretation and data collection can be found at:http://www.plasticseurope.org/plastics-sustainability-14017/life-cyclethinking-1746/eco-profiles-programme.aspx
} 


\section{Results and Discussion}

Table 1 shows the UEVs calculated for PET and for 10 of its precursors. The calculation was performed using emergy tables to quantify the emergy contributions of input flows to the production system for $1 \mathrm{~kg}$ of each product. The different UEVs determined represent the emergy intensities per gram of product (seJ /g). Table 1 also shows the UEVs previously calculated by other authors $[2,4,5]$. Differences may be attributed to assumptions for the calculation and to the processes intrinsic characteristics. In the case of ethylene, Sha et al. [4] assumes a yield of $31 \%$ of ethylene based on naphtha and considers other coproducts of the steam cracking process. Differently, the UEVs of this work are result of tracking back the inflows that belong to production route of $1 \mathrm{~kg}$ of ethylene (the same for all other products). Therefore, instead of yield conversion of the raw material, it is taken into account the elementary feedstock content in the product, i.e. crude oil through naphtha, tracked back to the first stage of the production chain (crude oil extraction). In this regard, it is worth noting that naphtha and other petroleum derivatives are not considered as co-products, but as splits of crude oil with different densities [3].

Table 1. Calculated unit emergy values (UEV) by product of the PET production chain and literature values.

\begin{tabular}{lccc}
\hline & $\begin{array}{c}\text { UEVs*/ } \\
\mathbf{x 1 0} \mathbf{~}^{*} \mathbf{( s e J / g ) *}\end{array}$ & $\begin{array}{c}\text { UEVs**from } \\
\text { literature } \\
(\mathbf{s e J} / \mathbf{g})^{*}\end{array}$ & Reference \\
\hline Crude Oil & 4.47 & $3.90 \times 10^{9}$ & {$[2]$} \\
Natural gas & 4.14 & $3.69 \times 10^{9}$ & {$[2]$} \\
Naphtha & 4.75 & $5.02 \times 10^{9}$ & {$[4]$} \\
Py gas & 5.77 & & \\
Xylene & 5.24 & & \\
P-Xylene & 6.15 & & \\
Ethylene & 6.40 & $1.69 \times 10^{10}$ & {$[4]$} \\
Ethylene oxide & 5.40 & & \\
Ethylene glycol & 3.99 & & \\
PTA & 5.00 & & \\
PET & 5.94 & $6.32 \times 10^{10}$ & {$[4]$} \\
\hline
\end{tabular}

\footnotetext{
* All the emergy measures in this work are related to baseline $15.83 \times 10^{24} \mathrm{seJ} /$ year [15].

** Calorific values between mass and energy in [2]: $4.19 \times 10^{4} \mathrm{~J} / \mathrm{g}$ for oil, and $5.13 \times 10^{4} \mathrm{~J} / \mathrm{g}$ for natural gas.
}

Regarding to the specific emergy of PET, the differences observed correspond to dissimilar levels of efficiency in the use of resources for production. However, there is some uncertainty by evaluating and comparing production systems from different countries or regions, since the emergy results do not directly reflect dif- 
ferences between systems for reasons other than technological, e.g., political or socio-economic aspects. Therefore, lower UEVs are the outcome of the highest efficiencies in the use of resources in highly industrialized countries or regions with advanced production technology. In this way, the emergy results can contribute in selecting production technologies with lower environmental costs, ensuring a more appropriate technological configuration for the use of resources. In parallel, these results can be interpreted as measures of quality of energy by defining ratios between amounts of emergy required per joule of product, i.e., transformities (seJ /J). Thus, an estimate of the process efficiency, in terms of emergy, is obtained (Fig. 2). The transformity increases linearly along the production chain, as more inputs (energy and materials) are incorporated into the chain to obtain the next derivative.

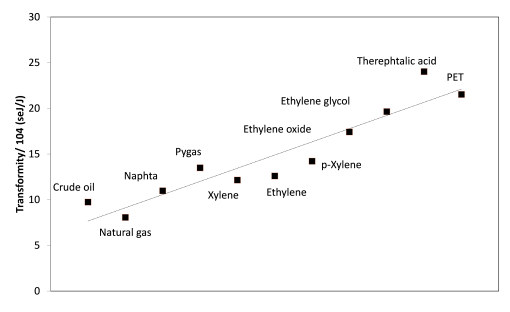

Fig. 2. Transformity values for derivatives of the PET production chain

This result also establishes an expected range for UEVs of the petrochemical industry. From crude oil to the final product, the transformity approximately doubles its value, and all UEV's estimated lie within a range between $3.99 \times 10^{9}$ seJ /g, from ethylene glycol, and, $6.40 \times 10^{9}$ seJ /g, from ethylene, which is the derivative with the largest emergy required per gram of the products of the chain. The tendency line also establishes the rate in which petrochemical transformations occur in the PET production chain. The expected range reduces the level of uncertainty in the UEVs selection for emergy estimations in the petrochemical industry, offering a possible alternative for future research to facilitate scientific and operative work on data collection to calculate UEVs in this sector.

\section{Conclusions}

In current scientific publications, emergy synthesis has been sparsely applied to the downstream production processes of extraction and refining of fossil fuels. In this article, the PET production chain was analyzed, from the perspective of resources and energy usage comprising a variety of intermediate products. The UEVs for petrochemical products were calculated and compared with the already existing in the literature; some of them are novel information (pyrolysis gas, xylene, para-xylene, ethylene oxide, ethylene glycol and purified terephthalic 
acid). Thus, this work contributes to the consolidation of the emergy databases and proposes an expectance range for the petrochemical industry as an approach that can be useful by applying the emergy method.

According to this study, it is considered that the use of LCIs in accounting emergy is a feasible and practical way to obtain reliable results. Additionally, it offers important contributions for integration and/or complementarity of both LCA and emergy methods.

\section{References}

1. Odum, H.T.: Environmental Accounting: Emergy and Environmental Decision Making. John Wiley \& Sons, New York (1996)

2. Bastianoni, S., Campbell, D., Susani, L., Tiezzi, E.: The Solar Transformity of Oil and Petroleum Natural Gas. Ecological Modelling 186(2), 212-220 (2005)

3. Bastianoni, S., Campbell, D., Ridolfi, R., Pulselli, F.: The Solar Transformity of Petroleum Fuels. Ecological Modelling 220(1), 40-50 (2009)

4. Sha, S., Melin, K., de Kokkonen, D.V., Hurme, M.: Solar Energy Footprint of Ethylene Processes. Ecological Engineering 82, 15-25 (2015)

5. Morales, M., Gonzalez-García, S., Aroca, G., Moreira, M.T.: Life Cycle Assessment of Gasoline Production and Use in Chile. Science of The Total Environment 505, 833-843 (2015)

6. Portha, J.F., Louret, S., Pons, M.N., Jaubert, J.N.: Estimation of the Environmental Impact of a Petrochemical Process Using Coupled LCA and Exergy Analysis. Resources, Conservation and Recycling 54(5), 291-298 (2010)

7. Raugei, M., Bargigli, M., Ulgiati, S.: "Nested Emergy Analyses": Moving Ahead from the Spreadsheet Platform. In: Proceedings from the Fourth Biennial Emergy Conference, Gainesville, Florida (2007)

8. Bakshi, B.R.: A thermodynamic Framework for Ecologically Conscious Process Systems Engineering. Computers \& Chemical Engineering 26(2), 269-282 (2002)

9. Rugani, B., Benetto, E.: Improvements to Emergy Evaluations by Using Life Cycle Assessment. Environmental Science \& Technology 46(9), 4701-4712 (2012)

10. Raugei, M., Rugani, B., Benetto, E., Ingwersen, W.W.: Integrating Emergy into LCA: Potential Added Value and Lingering Obstacles. Ecological Modelling 271, 4-9 (2014)

11. Almeida, C., Rodrigues, A., Bonilla, S., Giannetti, B.: Emergy as a Tool for Ecodesign: Evaluating Materials Selection for Beverage Packages in Brazil. Journal of Cleaner Production 18(1), 32-43 (2010)

12. PlasticsEurope: Eco-profiles and Environmental Product Declarations of the European Plastics Manufacturers - Polyethylene Terephthalate (PET) Bottle-Grade. Tech. rep. (2012)

13. Ulgiati, S., Zucaro, A., Franzese, P.P.: Shared Wealth or Nobody's Land? The Worth of Natural Capital and Ecosystem Services. Ecological Economics 70(4), 778-787 (2011)

14. Association of European Plastics Manufacturers, PlasticsEurope, http://www . plasticseurope.org/

15. Odum, H.T.: Folio \#2: Emergy of Global Processes. Handbook of Emergy Evaluation, Center for Environmental Policy, Florida (2000) 